\title{
MIMESIS TRIPARTIDA, UMA LEITURA HERMENÊUTICA DE “O ALMADA" DE MACHADO DE ASSIS
}

\section{THREEFOLD MIMESIS, AN HERMENEUTIC APPROACH TO THE POEM “O ALMADA", OF MACHADO DE ASSIS}

\author{
Adna Candido de Paula*
}

RESUMO: O presente artigo tem por objetivo apresentar uma leitura hermenêutica do poema "O Almada" de Machado de Assis. Será abordada nessa análise a intertextualidade, explicitamente evocada pelo poeta na Advertência que antecede o poema, com os poemas "O Hissope" de Antônio Diniz da Cruz e Silva e "Le Lutrin" de Nicolas Boileau. Outrossim, a análise problematiza a relação entre o conceito de "triple mimèsis" postulada por Paul Ricoeur e a representação sociocultural do poema.

PALAVRAS-CHAVE: Poesia, Machado de Assis, Mimesis, Paul Ricoeur, Hermenêutica.

ABSTRACT: The article aims at presenting an hermeneutic approach to the poem "O Almada", of Machado de Assis. It will be emphasised the "intertextuality" evoked by the author in the section antedating the poem, which discusses two poems: "O Hissope" (Antônio Diniz da Cruz e Silva) and "Le Lutrin" (Nicolas Boileau). The text also discusses the relationship between Paul Ricouer's conception of "triple mimèsis" and the socio-cultural representations of Assis' poem. KEY WORDS: Poetry, Machado de Assis, Mimesis, Paul Ricoeur, Hermeneutics.

\footnotetext{
* Pós-doutoranda da Universidade Estadual de Campinas, bolsista da Fundação de Amparo à Pesquisa do Estado de São Paulo. Email: adnapaula@ yahoo.com.br.
} 



\section{MIMESIS TRIPARTIDA, UMA LEITURA HERMENÊUTICA \\ DE “O ALMADA" DE MACHADO DE ASSIS}

"É um perigo para o poeta assinalar-se fortemente nos domínios da prosa”. Com essa frase, Manuel Bandeira inicia suas considerações acerca do poeta Machado de Assis. Esse texto, que foi utilizado pela Editora Nova Aguilar como introdução às "Poesias Completas" de Machado de Assis, apresenta uma constatação que freqüentemente aparece nas análises sobre a poesia machadiana. De uma maneira geral, como observou o Professor Cláudio Murilo Leal ${ }^{1}$, os críticos consideram que, em poesia, Machado de Assis não se revelou tão genial quanto na prosa, mas tanto ele, quanto o professor Mário Chamie e outros tentam mostrar que o gênero poético machadiano não está distante dos demais gêneros empreendidos pelo escritor: a crônica, o romance, o teatro, o conto e a crítica. Ao contrário, é possível perceber, à luz de uma leitura global da obra de Machado de Assis, que esses gêneros dialogam entre si e que apresentam características comuns. É provável que essa intertextualidade interna da obra de Machado de Assis seja a responsável por uma das características marcantes de sua poesia, a dimensão narrativa. A poesia narrativa, que tem origem clássica,

\footnotetext{
${ }^{1}$ A conferência "A vocação narrativa da poesia de Machado de Assis" foi proferida pelo Professor Cláudio Murilo Leal, no dia 28 de novembro de 2000, no Ciclo de Conferências "Machado de Assis Cronista e Poeta" organizado pela Academia Brasileira de Letras.
} 
com a epopéia e a tragédia, interessa ser investigada naquilo que oferece como elemento próprio - o limite entre prosa e poesia, as contribuições mútuas e as especificidades que não são comutáveis. Mas antes de tratar da poesia, especificamente, vale, a título de informação, considerar alguns dados arrolados pelo professor Leal em sua pesquisa doutoral. Segundo ele, existem quarenta e dois ensaios, artigos e resenhas em jornais e revistas sobre a poesia de Machado, inéditos em livro, na Biblioteca Nacional, no Gabinete Português de Leitura, na Casa de Rui Barbosa e na Academia Brasileira de Letras. Não é uma produção de grande vulto se considerarmos o que já foi produzido e o que ainda está sendo produzindo, levando em conta as dissertações de mestrado e as teses de doutorado, a respeito da prosa machadiana, mas é sem dúvida um número relevante, indicativo da atenção que a poesia de Machado de Assis suscita e merece. Ainda segundo Leal, Machado de Assis publicou duzentos e setenta e oito poemas e quase vinte e um mil versos: Crisálidas, publicado em 1864; Falenas, em 1870; Americanas, em 1875, e Ocidentais, que foi publicado com as Poesias completas, em 1891; além de poemas esparsos publicados em revistas e jornais da época.

A leitura de Poesias completas nos permite perceber um gama de poemas cuja temática é romântica, ainda não influenciada pela escola realistanaturalista francesa. O idealismo romântico aparece nos poemas dos três livros. Temos, por exemplo, o poema "A Mosca Azul" que é uma releitura da "flor azul" de Novalis. À estrutura dessas poesias se misturam a rigidez do parnasianismo e a sonoridade e mistério do simbolismo. Machado de Assis não parece ter sido influenciado pela "Geração de 70" portuguesa, que apresentou em suas poesias a crítica social, alimentada pelo materialismo dialético, e o cientificismo, proporcionado pelo advento das ciências naturais. Fato é que os poetas homenageados em sua poesia são: Alfred de Musset, Shakespeare, Lamartine, Gonçalves Crespo, entre outros. Misturados aos poemas temos algumas traduções, tais como: "A Elvira" de Lamartine, "O Corvo" de Edgar Allan Poe, "To be or not to be" de Shakespeare e "Os Deuses da Grécia" de Schiller.

O presente artigo analisa o poema "O Almada" designado como: "Poema Heróico-Cômico em 8 cantos”. Na verdade, trata-se de fragmentos do poema, visto que alguns cantos inteiros foram suprimidos, ao que tudo indica, por orientação do próprio poeta. O poema é antecedido por uma "Advertência" e é pela análise de alguns pontos dessa que iniciamos esse 
trabalho. A primeira frase desse texto introdutório oferece-nos a seguinte informação: $O$ assunto deste poema é rigorosamente histórico. E assim é resumido o fato:

Em 1659, era prelado o administrador do Rio de Janeiro o Dr. Manuel de Sousa Almada, presbítero do hábito de S. Pedro. Um tabelião, por nome Sebastião Ferreira Freire foi vítima de uma assuada, em certa noite, na ocasião em que se recolhia para casa. Queixando-se ao ouvidor-geral Pedro Mustre Portugal, abriu este devassa, vindo a saber-se que eram autores do delito alguns fâmulos do prelado. O prelado, apenas teve notícia do procedimento do ouvidor, mandou intimá-lo para que lhe fizesse entrega da devassa no prazo de três dias, sob pena de excomunhão. Não obedecendo o ouvidor, foi excomungado na ocasião em que embarcava para a capitania do Espírito Santo. Pedro de Mustre suspendeu a viagem e foi à Câmara apresentar um Protesto em nome do rei. Os vereadores comunicaram a notícias do caso ao governador de cidade, Tomé Alvarenga; por ordem deste foram convocados alguns teólogos, licenciados, o reitor do colégio, o dom Abade, o Prior dos Carmelitas, o guardião dos Franciscanos, e todos unanimente resolveram suspender a excomunhão do ouvidor e remeter todo o processo ao rei. (ASSIS, 2006, p. 227)

A Advertência tem uma função muito peculiar à literatura moderna, a da metalinguagem, ou metaliteratura, cujo paradigma é "A filosofia da composição" de Edgar Allan Poe. Machado de Assis apresenta nessa advertência os elementos e as escolhas estruturais que fez na composição do poema "O Almada". Para além do fato histórico, acima reproduzido, o poeta procura categorizar sua produção dentro do gênero paródia, respeitando a designação dada às obras parodiadas - O Hissope, poema herói-cômico de Antonio Diniz da Cruz e silva e Le Lutrin, poème héroüco-comique de Nicolas Boileau-Despréaux. Enfim, trata-se de uma paródia herói-cômico. Cabe a essa análise perceber cada uma das designações que compõem o gênero de "O Almada" e, para tanto, é necessário empreender um processo investigativo. Em que medida o poema é uma paródia? Quais características do gênero heróico, épico ou trágico, o texto comporta? Qual a dimensão da comicidade presente no texto? A melhor forma de investigar o alcance da paródia no poema de Machado de Assis é perceber a extensão da intertextualidade entre esse e as duas outras obras. Considerando o ano de publicação dessas, devemos iniciar a análise com Le Lutrin. 
O poema foi publicado em 1674 com apenas os quatro primeiros cantos; os dois últimos foram publicados em 1683. A primeira característica e a mais marcante do gênero heróico, ou épico, é a estruturação do poema na três partes características das epopéias clássicas: Proposição, Invocação e Narração. Assim se apresenta a proposição de Boileau:

Je chante les combats, et ce prélat terrible

Qui par ses longs travaux et sa force invincible,

Dans une illustre église exerçant son grand coeur,

Fit placer à la fin un lutrin dans le choeur.

C'est en vain que le chantre, abusant d'un faux titre,

Deux fois l'en fit ôter par les mains du chapitre:

Ce prélat, sur le banc de son rival altier

Deux fois le reportant, l'en couvrit tout entier. (BOILEAU, Canto I)

O poeta português, Antonio Diniz, publica seu poema em 1817 e igualmente faz uso de Proposição: Eu canto o BISPO, e a espantosa guerra,/ Que o HISSOPE excitou na Igreja d'Elvas. Machado de Assis faz uma inversão, apresenta na primeira parte do primeiro canto, tanto a Invocação quanto a Proposição, sendo que essa última vem em segundo plano: A magna causa e a temerosa guerra/ Que viu desatinado um povo inteiro,/ Homens do foro, almotacés, Senado,/ Oficiais do exército e do fisco,/ Provinciais, abades e priores,/ E quantos mais, a uma defendiam/ O povo, a Igreja e a régia autoridade. As três obras apresentam a segunda parte da epopéia clássica - a Invocação. Nesse ponto, podemos perceber que há uma reação em cadeia presente na intertextualidade dessas obras. A Invocação de Boileau, por ser a primeira obra dessa tríade, não reporta a nenhuma outra: Muse redis-mois donc quelle ardeur de vengeance/ De ces hommes sacrés rompit l'intelligence,/ Et troubla si longtemps deux célèbres rivaux. Antonio Diniz, na seqüência, faz sua Invocação assumindo a filiação de sua obra à de Boileau:

Musa, Tu, que nas margens aprazíveis,

Que o Sena borda de árvores viçosas,

Do famoso Boileau a fértil mente

Inflamaste benigna, Tu me inflama;

Tu me lembra o motivo; $\mathrm{Tu}$, as causas, 
Por que a tanto furor, a tanta raiva

Chegaram o Prelado, e o seu Cabido. (CRUZ E SILVA, Canto I)

Machado de Assis, em sua Invocação, fecha o ciclo da intertextualidade reafirmando a filiação que já anunciou na Advertência. Para tanto, além de citar Boileau, utiliza-se do pseudônimo de Antonio Diniz - Elpino Nonacriense:

MUSA, CELEBRA a cólera do Almada

Que a fluminense igreja encheu de assombro.

E se ao douto Boileau, se ao grave Elpino

Os cantos inspirastes, e lhes teceste

Com dóceis mãos as imortais capelas,

Perdoa se me atrevo de afrontá-la

Esta empresa tamanha. [...] (ASSIS, Canto I)

Após a Invocação, segue a Narração para todos. Interessante é observar que Antonio Diniz, compatrício do maior poeta épico português, não seguiu seus passos incluindo uma Dedicatória à estrutura interna do poema. O espaço geográfico que serve como pano de fundo é diverso nos três poemas, apesar de "O Hissope" e "Le Lutrin" terem sido publicados em Paris. A história de Boileau se passa na França, na cidade de Paris. Já o poema de Antonio Diniz tem como palco uma cidade portuguesa - Elvas. A descrição feita por Machado de Assis do local onde se deu a contenda que narra cria uma bela imagem romântica de um Brasil colonizado:

Deixa que o véu dos séculos rompendo

A minha voz ressurja a infância tua.

Viveremos um dia aquele tempo

De original rudez, quando a primeira

Cor que se te mudou do muito afago

De mãos estranhas e de alheias tintas,

A tosca, ingênua fronte te adornava,

Não de jóias pesadas, mas viçosa

De folhagens agrestes. Quão mudada

Minha volúvel terra! Que da infância

Te poliu a rudez pura e singela? (ASSIS, Canto I) 
As três obras, como vimos, tem por mote uma disputa que envolve membros da igreja. A diferença é que nos dois primeiros casos - "O Hissope" e "Le Lutrin" - a disputa se dá entre membros da própria igreja, o que não se reproduz no poema de Machado de Assis. Em "Le Lutrin", o combate se dá entre o Prélat [prelado] e o Chantre [chefe do coro] e o que alimenta a contenda é a inveja e o orgulho que o primeiro sente em relação ao sucesso do segundo e, de acordo com o Prélat, é inadmissível a intromissão do Chantre em atividades que lhe competem. Já em "O Hissope", a discórdia se dá entre o Deão e o gordo bispo, seu superior, e trata-se de um caso de insubordinação por parte do primeiro que o ego do segundo não pôde admitir. $\mathrm{O}$ que fomenta essas disputas representa mais uma característica do gênero heróico - a intervenção de divindades que, sorrateiramente, alimentam o ânimo dos contendores. Assim como Vênus e Baco, em disputa, interferiam no destino dos portugueses em Os lusíadas, em "O Hissope" a divindade Senhoria tenta impedir o cumprimento da ordem do Gênio tutelar das Bagatelas, que é representado com as mesmas características de Zeus, o deus supremo do Olimpo. O Gênio decide, em assembleia com as demais divindades, premiar o gordo bispo, por conta de sua atenção para com as bagatelas, as coisas ridículas e fúteis, fazendo com que o Deão lhe vá à porta esperar com o hissope. A Senhoria, que é constantemente honrada na casa do Deão, não é favorável à decisão do Gênio das bagatelas e confessa sua opinião no que é rechaçada pela Excelência, outra divindade. Esse agravo empreendido pela Excelência é suficiente para provocar a ira da Senhoria, que fomentará a recusa do Deão em cumprir as ordens do gordo Bispo. No caso de "Le Lutrin", a divindade Discorde é quem alimenta no Prélat o ciúmes do Chantre, despertando nesse o desejo de vingança. Seguindo os conselhos da Discorde, recebidos durante o sono, o Prélat ordena seus subordinados a atentarem contra o Chantre. Por um instante, outras forças divinais - la Mollesse e la Nuit - quase frustram o intento do Prélat, mas a Discorde restabelece as forças e intenções de seus cúmplices:

Songez quel déshonneur va souiller votre gloire, Quand le chantre demain entendra sa victoire.

Vous verrez tous les jours le chanoine insolent, Au seul mot de hibou, vous sourire en parlant.

Votre âme, à ce penser, de colère murmure :

Allez donc de ce pas en prévenir l'injure ; 
Méritez les lauriers qui vous sont réservés,

Et ressouvenez-vous quel prélat vous servez. (BOILEAU, Canto III)

Não foi a primeira vez que o Prélat agiu contra o Chantre, le prélat trop jaloux lui rogna de trois doigts. No poema de Machado de Assis, as divindades também agem, e, ali, a Discórdia, presente tanto em "O Hissope" quanto em "Le Lutrin", recebe a denominação de Ira: Porém a Ira, a quem blasfêmias prazem, / A tempo chega e lhe desata a língua. Nos três poemas temos um desfile de divindades que tomam a forma humana, ou características humanas como uma fala mansa, a fim de sugestionar e manipular as personagens, sobretudo aquelas envolvidas diretamente nas contendas. São as divindades que controlam o "destino" dos humanos. Por exemplo, a guerra interna da igreja, em "Le Lutrin", só teve lugar porque as boas divindades estavam de férias, e são elas que, no regresso rápido, restabelecem a ordem e a paz:

Tandis que tout conspire à la guerre sacrée,

La Piété sincère, aux Alpes retirée,

$\mathrm{Du}$ fond de son désert entend les tristes cris,

De ses sujets cachés dans les murs de Paris.

Elle quitte à l'instant sa retraite divine

La Foi, d'un pas certain, devant elle chemine ;

L'Espérance au front gai l'appuie et la conduit ;

Et, la bourse à la main, la Charité la suit. (BOILEAU, Canto VI)

Dois mundos se configuram e exercem influências mútuas, essa é, sem dúvida, a característica mais marcante do gênero heróico a que os três poetas se reportam ao classificar seus poemas. Considerando que a mais antiga das três obras foi publicada no século XVII, um século depois da publicação de Os lusíadas, que é o épico emblemático na representação renascentista da mistura entre a cultura greco-latina e os elementos do cristianismo, outra característica épica presente nesses poemas é exatamente a da imbricação dessas duas vertentes culturais. Nessas obras, as divindades não recebem nomes de deuses gregos, mas agem da mesma forma e com o mesmo poder de decisão sobre os humanos. Os nomes dados a essas divindades são nomes de virtudes teologais (Fé, Esperança, Piedade), e de pecados capitais (Gula, Preguiça, Ira). Vale ressaltar que na obra de Machado de Assis 
não existe a dicotomia bem/mal, todas as divindades são do grupo dos sete pecados capitais.

Quanto à comicidade, alguns trechos são dignos de nota, para além da caracterização físico-psicológica das personagens, sobre a qual falaremos adiante. Por exemplo, em "Le Lutrin", a guerra de livros que acontece na livraria entre, de um lado, o Prélat e seus comparsas e, de outro, o Chantre e os seus: Les volumes, sans choix à la tête jetés,/ Sur le perron poudreux volent de tous côtés:/ Là, près d'un Guarini, Térence tombe à terre;/ Là, Xénophon dans l'air heurte contre un la Serre,/ Oh! que décrits obscurs, de livres ignorés,/ Furent en ce grand jour de la poudre tirés! É uma sátira explícita à desvalorização da cultura, da literatura mais especificamente. Livros relevantes, que mantêm a poeira acumulada sobre eles ao longo dos anos em que não foram manuseados, e muito menos lidos, servem de arma em uma guerra mesquinha de egos feridos. Outro episódio cômico que se destaca é, segundo Machado de Assis, parodiado por Antonio Diniz do canto XIX da Ilíada, cena em que o cavalo de Aquiles - Xanto - inspirado pela deusa Hera, anuncia sua morte. Em "O Hissope" é o episódio do vaticínio do galo assado, que se levanta do prato e ameaça o Deão:

O velho Galo, que num prato estava,

Entre frangões e pombos, lardeado,

Em pé se levantou, e as nuas asas

Três vezes sacudindo, estas palavras,

Em voz articulou triste, mas clara:

- "Em vão, cruel Deão, em vão celebras

Com nosso sangue o próspero sucesso,

Que a futura vitória te promete;

Que por fim cederás a teu contrário." (CRUZ E SILVA, Canto VII)

No poema de Machado de Assis, como ele próprio anunciou na Advertência, a comicidade é garantida no contraste da causa com os efeitos, tão graves, tão solenes, tão fora de proporção. Além desses exageros intencionais, para garantir o risível característico da paródia, outra forma encontrada por Machado de Assis foi a construção de uma "comédia de costumes" à sa manière, e nessa caracterização de sujeitos sociais se encontra a crítica a comportamentos e ações. Vejamos somente mais um elemento de intertextualidade parodiado pelos escritores desses três poemas, antes de 
analisar especificamente "O Almada". Machado de Assis confessa ter imitado, no canto IV, o episódio de Heitor e Andrômaca, na Ilíada. Segundo ele, os outros dois poetas imitaram, da Eneida, o episódio de Dido e Enéias, mas os três são análogos ao parodiar a relação amor-dever. A resignação diante do dever a cumprir, sofrendo com a perda da própria vida e também do amor é tema heróico, tanto nas epopéias quanto nas tragédias clássicas, mas nesses três poemas a paródia torna ridícula tal resignação diante do mesquinho dever. Em "Le Lutrin", a cena parodiada é protagonizada pelo fameux perruquier e sua esposa Anne, la perruquière. Anne implora ao marido que não cumpra a missão do Prélat contra o Chantre, mas o perruquier, usando o discurso do dever a cumprir, lembra-lhe a que forças serve: Que te dirai-je enfin? C'est le ciel qui mappelle,/ Une église, un prélat méngage en sa querelle,/ Il faut partir: j'y cours. Dissipe tes douleurs, / Et ne me trouble plus par ces indignes pleurs. Em "O Hissope", o diálogo e apelo amoroso também se dá entre um casal "lícito". A esposa de Gonçalves, o escrivão atrevido que não demonstra medo diante do poder do gordo Bispo, aceita a missão do Deão e vai entregar a apelação. Seu discurso de consolo à esposa, diferente do perruquier, se aproxima mais do discurso dos textos heróicos, onde o valor da missão está acima do medo da represália. Contudo, o escrivão não se sente cumprindo seu fado, como ocorria com os heróis clássicos, mas defende sua missão pela força do trabalho, uma concepção moderna de "dever" que nada tem a ver com valores éticos ou morais:

“- Enxuga o belo pranto, oh bela Esposa,

Que sem causa derramas, pois com ele

$\mathrm{O}$ forte coração me despedaças.

Eu não vou combater algum Gigante,

Nem tenho o Tamorlão por inimigo;

Vou fazer meu ofício, e bem conheço

A quanto me abalanço, e me aventuro.

Mas que dirá o Mundo, se vir hoje,

Que eu fujo dos trabalhos com o corpo?

De mais, que deste excesso, a que me arrojo,

Tu a causa só és; pois d’outra sorte

Mal poderei, Meu rico Bem, compra-te

A Saia, a Capa, a Fita, o Leque, o Pente.

Os anos estão caros, e eu não devo 
Um gancho desprezar, que raras vezes

A Ventura depara, e nos oferece. (CRUZ E SILVA, Canto VI)

Em "O Almada”, o discurso de Brígida, mescla robusta de áfrico sangue e sangue d'alva Europa, se aproxima em muito do discurso de Andrômaca, que em vão tenta dissuadir Heitor de sua missão. A paródia, nesse caso, está no fato de Cardoso, o mensageiro do Almada que entrega a intimação com a ameaça de excomunhão ao Mustre, ser padre. O próprio Machado de Assis pergunta em nota se era necessário explicar que "padrinho" era um eufemismo: A idéia de perder-vos me acobarda./ Que será desta mísera criança,/ Se o padrinho lhe falta, e sem conforto,/ Nem amparo, nem mão experientel Houver de caminhar do berço à campa? Como foi mencionado acima, a comicidade está presente na descrição do comportamento de indivíduos da sociedade brasileira do século XIX. Ao final de sua Advertência, Machado de Assis desculpa-se com a igreja afirmando não ter tido a intenção de faltar com o respeito devido ao clero e às coisas da religião. Justifica-se dizendo que, como era do conhecimento de todos, o clero da época era mais passível de escárnio que respeito, assim como o afirmou o Padre Manuel da Nóbrega, da Companhia de Jesus: Os clérigos desta terra têm mais ofícios de demônios que de clérigos. Em "O Almada", a divindade Ira, tão fortemente presente nas três obras, divide a cena com outra divindade que mais caracteriza todo o clero, a Gula. É uma disputa acirrada entre as divindades por domínios de ação e influência: Deste jeito falando a voraz Gula,/ Os brios da Preguiça abala e acorda./ E a lembrança lhe traz desconsolada/ De quantas vezes a terrível Ira/ As obras malogrou das artes suas. Aliás, a presença da Gula tão incidente na vida dos clérigos, expõe a animalidade desses glutões, assim como fez Eça de Queiroz em O crime do padre Amaro. A comida passa a ser, no poema, uma forma de barganha, visto que, o Almada, a fim de conseguir apoio dos demais membros da igreja, manda preparar um banquete com as melhores iguarias servidas nos mais refinados pratos e talheres:

\section{Então o Lucas}

Que, desde que estreara a lauta mesa,

Come com quantos dentes tem na boca,

Que uma assada cutia despachara,

Quatro pombos, e de uma garrafa torta 
Ia já caminhando em mais de meio,

A boca levantou do eterno pasto

E falou dessa sorte: "Bem humilde

É meu braço, senhor; mas se a defesa

Dos sacros foros meu esforço pede,

Contar podeis comigo neste lance,

E certo estou que em decisão e zelo

Ninguém me há de exceder". (ASSIS, Canto III)

Essa preocupação explícita do poeta em se justificar pelo realismo utilizado na caracterização dos personagens, além do cuidado em assumir que seu poema se baseava num fato histórico refuta a idéia de que Machado de Assis não tinha visão do mundo exterior, que ele não se preocupava com os problemas sociais. É óbvio, e mesmo uma leitura plana o pode atestar, que a poesia machadiana está bem distante da poesia de crítica social, da poesia de panfleto. $\mathrm{O}$ que não equivale a dizer que o mundo externo não esteja presente nessa poesia. O próprio processo de construção do poema "O Almada" demonstra isso, além da intenção expressamente anunciada pelo poeta: Numa obra deste gênero pode-se e deve-se alterar a realidade dos fatos, quando assim convenha ao plano da composição; mas as feições gerais do tempo e da sociedade, a essas é necessária a fidelidade histórica. (ASSIS, 2006, p. 229).

Primeiro Platão, com a República, e depois Aristóteles, com a Poética, foram os primeiros teóricos a perceber que a literatura "imita" o real, produzem a mimesis dos comportamentos e ações humanas. Modernamente, o filósofo Paul Ricoeur propõe uma junção entre a idéia de intriga, cara a Aristóteles, e as reflexões de Agostinho sobre o tempo. Para Ricoeur, há uma correlação entre a atividade de contar uma história e o caráter temporal da experiência humana. A idéia central da tese de Ricoeur concentra-se na avaliação da ação, do agir humano, e, para chegar à construção da hipótese de que o sujeito se interpreta interpretando narrativas, ele recupera dois conceitos aristotélicos: o da construção do enredo (mythos) e o da atividade mimética (mimesis). A fim de explorar a mediação entre tempo e narrativa, Ricoeur, a partir da separação empreendida anteriormente por Aristóteles de mimesis-mythos-catharsis, divide o processo da mimesis em três momentos e os denomina da seguinte forma: mimesis I, II e III. Esse procedimento é valioso para que a hermenêutica possa cumprir com a sua 
tarefa - a de reconstruire l'ensemble des opérations par lesquelles une oeuvre senlève sur le fond opaque du vivre, de l'agir et du souffrir, pour être donnée par un auteur à un lecteur qui la reçoit et ainsi change son agir. (RICOEUR, 1983, p. 106-107).

Em mimesis I, também denominada como prefiguração, temos a précompreensão do mundo da ação em todos os seus domínios, naquilo que ela objetiva, no que ela causa e nos seus potenciais agentes. Ou seja, é a investigação do mundo real a ser configurado, é o tempo da ação, do vivido. Considerando o poema "O Almada”, o próprio poeta oferece indicações do mundo real que lhe serviu de base para a elaboração ficcional. A primeira delas, citada no início desse artigo, é o fato histórico, a determinação geográfica e temporal - Rio de Janeiro, 1659. A segunda marca temporal e espacial se encontra na terceira parte do canto I: Reinaval Afonso VI. Da coroa em nome/ Governava Alvarenga, incorruptível/ No serviço do rei, astuto e manso. Outros dados se somam a esse determinando a vida social e cultural. Por exemplo, na descrição da atividade econômica do pai de Margarida, a pivô da disputa amorosa entre Vasco, o sobrinho do Prelado, e Freire, o tabelião da cidade: Que o pai, varão de bolsa e qualidade,/ Que repousava das fadigas longas/ Havidas no mercado de africanos; e ainda no mesmo canto III: Do ríspido negreiro; a esposa o segue,/ E logo atrás a suspirada moça. Não se trata de realismo puro, ou imitação. Esse reconhecimento do mundo real, essas pequenas marcas, são necessárias para que haja interpretação. Sem reconhecimento não há trabalho hermenêutico possível, pois a referência primeira se perde e o leitor não consegue alcançar o segundo sentido das referências presentes no texto. Sem reconhecimento, há leitura, mas não há interpretação, pois não há nada no texto passível de ser interpretado. A ficção cria em cima de uma linguagem acessível, com elementos plurais da referência primeira, do mundo real, ou seja, ela tem uma liberdade relativa e Machado de Assis demonstra estar consciente disso: No poema estão os principais elementos da história, com as modificações e acréscimos que é de regra e direito fazer numa obra de imaginação.

A mimesis II representa a configuração, é o momento da ficcionalização dos dados investigados em mimesis I. É o momento artístico, propriamente dito, o do trabalho de composição do enredo, onde o poeta reconfigura o heterogêneo, ou seja, o tempo e o espaço real. Segundo Ricoeur, a construção do enredo organiza um todo onde estão presentes os eventos, os incidentes individuais, os agentes, os objetivos, os meios, as interações, as 
circunstâncias, os imprevistos, tudo isso dentro de um espaço e tempo que tem por referência o real. O que a ficção cria é um novo mundo, que Ricoeur denomina como um mundo passível de ser habitado. O processo de ficcionalização empreendido por Machado de Assis na elaboração de "O Almada” já vem descrito na Advertência. Mas, sem a presença da Advertência também seria possível depreendê-lo, através do primeiro momento do ato de leitura, o da decodificação dos símbolos. Essa decodificação tem a ver com as etapas da tarefa hermenêutica, ou seja, o leitor identifica as referências e estabelece, ele mesmo, assim como fazem os críticos literários, o processo investigativo. Machado de Assis ficcionalizou um fato histórico, somou a esse a intertextualidade com dois outros poemas de diferentes autores, publicados em períodos históricos diversos, procurou se enquadrar num determinado gênero literário e desenhou perfis críticos de personagens comuns ao seu próprio período histórico. Existe ainda presente no poema a "assinatura" do escritor, aquilo que nunca falta numa obra machadiana. $\mathrm{O}$ escritor estrategista, que demonstrar ter total consciência do seu processo criativo, assim como Allan Poe, e que se diverte em conduzir o leitor no percurso inverso da criação, por isso, sempre que possível, estabelece com esse o diálogo direto ou indireto: Que lance há hi, nessa comédia humana,/ Em que não entrem moças? Descoradas,/ Como heroína de romance de hoje,/ Alva, como as mais alvas deste mundo,/ Tal que disseras the negara o sangue/ A madre natureza. A propósito, a história de amor entre Margarida e Freire é praticamente um récit-enchâssé. Afinal, mesmo tendo sido o atentado de Vasco, sobrinho do Prelado e preterido por Margarida, contra o Freire, o motivo da devassa que o Mustre abriu contra o Almada, nenhuma relevância tem esse fato na ponderação dos ânimos. A história de amor, o triângulo amoroso, o possível impedimento amoroso representado na figura do pai da donzela, o escravocrata, nenhum desses fatos tem relação direta com a contenda entre a igreja e a lei. Nem mesmo quando Vasco assume a responsabilidade do crime: "Ora pois! Fosse a causa amor ou ódio/ (O tio diz) importa nada ao caso,/ Nem por isso uma linha só recuo/ Do meu procedimento".

A terceira mimesis, a da refiguração, representa o ponto de chegada do texto literário, ou seja, o do ato de leitura, a recepção do texto pelo leitor. O que o leitor recebe não é somente o sentido da obra, mas a possibilidade de, através desse mundo desvelado, dessa experiência traduzida em linguagem, conhecer novos paradigmas de ações e de experiências. Em mimesis 
III, o leitor apropria-se desse mundo desvelado, que é um mundo cultural. De qualquer forma, o ciclo hermenêutico não se fecha com a mimesis III, pois na junção do mundo da obra com o mundo do leitor há uma dupla transformação. O leitor é transformado pelo texto pois, no ato de leitura, interpreta a si mesmo ao interpretar o novo mundo manifesto. Por outro lado, o leitor traz para o mundo da obra novos elementos que a completam, que intensificam a sua heterogeneidade. $\mathrm{O}$ ciclo não se fecha porque $\mathrm{o}$ ato de leitura tem o poder de descontextualizar uma obra literária e recontextualizá-la em diferentes momentos. Esse processo contínuo é fundamental para a história da humanidade, trata-se da oportunidade de rememoração contínua. Por exemplo, no poema de Machado de Assis, uma mácula da história é revivida pelo leitor contemporâneo e será também recontextualizada no futuro:

No cérebro agitado lhe traçava

A mão da Ira mil diversos planos

Contra o fero ouvidor. Ora imagina,

Em saco estreito atado na cintura,

Mandar deitá-lo aos peixes; longos anos

Encerrá-lo em medonho, escuro cárcere;

Ou já numa fogueira, concertava

Pelas discretas mãos do Santo Ofício,

Esmero d'arte e punição de hereges,

Como um simples judeu, torrá-lo aos poucos. (ASSIS, Canto IV)

O mundo desvelado pela recontextualização da obra literária expõe sujeitos agentes e situações. O leitor, graças ao distanciamento do mundo real promovido pelo ato de leitura, pode avaliar, julgar, compadecer-se, tomar partido, fazer escolhas nesse mundo ficcionalizado, escolhas e ações que irão interferir no seu mundo real. Não é possível mensurar o alcance e o efeito que a recontextualização de uma obra literária possa ter, mas essa é, sem dúvida, a característica mais marcante da literatura, a capacidade de sobreviver ao tempo e de permitir a transformação dos sentimentos e da história. Talvez por isso, a passagem do tempo e a possível observação dessa passagem façam do tempo um tema tão fascinante, tanto para os filósofos quanto para os literatos. O poder transformador do tempo, que a literatura tem a capacidade de manifestar também aparece no poema "O Almada": 
Obra do tempo foi o que tudo acaba,

Que as cidades transforma como os homens.

Agora a flor da juventude o seio,

Que as mantilhas despira de outra idade,

Graciosa enfeita; crescerás com ela

Até que vejas descambar no espaço

O último sol, e ao desmaiado lume

Alvejarem-te as cãs. Então, sentada

Sobre as ruínas últimas da vida,

Velha embora, ouvirá nas longas noites

A teus pés os soluções amorosos

Destas perpétuas águas, sempre moças (ASSIS, Canto I)

Para finalizar esse breve estudo, vejamos uma última intertextualidade entre os poemas de Machado de Assis e Antonio Diniz. Em "O Almada", no canto III em que o poeta insere a história de amor de Margarida e Freire, ao analisar as características psicológicas de Freire, o eu lírico faz a seguinte consideração: Como os outros mortais, morrer de amores; / E amar e ser amado é, neste mundo/ A tarefa melhor da nossa espécie,/ Tão cheia de outras que não valem nada. Essa consideração está diretamente ligada com a questão do tempo e com a da fragilidade humana, muito bem descrita nos versos de "O Hissope", no momento em que o Gênio das bagatelas profere sua decisão final para resolver a guerra "santa" entre o Deão e o gordo bispo:

É pois minha vontade, ordeno, e mando,

Sob pena de incorrer no desagrado

Do meu Real Favor, de abrir os olhos

Do mundo fascinado, e de mostrar-lhe

Que nada tem de real vossas Pessoas,

Que todos são fantásticas Quimeras:

É exatamente como Quimeras, como ficção e como sonho, que os homens procuram se compreender para além das bagatelas.

\section{Referências Bibliográficas}

ASSIS, Machado de. Obra completa. Volume III. Rio de Janeiro, Editora Nova Aguilar S.A., 2006. 
BOILEAU DESPREAUX, Nicolas. Oeuvres I: satires, le lutrin. Chronologie et introduction par Jerome Vercruysse. Paris: G. Flammarion, 1969.

CRUZ E SILVA, Antônio Diniz da. O hissope: poema herói-cômico em 8 cantos / reprodução de um manuscrito inédito do século XVIII. Prefácio e anotações de José Pereira Tavares. Lisboa: A. Pinto, [1950].

RICOEUR, Paul. Temps et récit, tome 1: L'intrigue et le récit historique. Paris: Le Seuil, 1983.

Recebido em 26 de novembro de 2007

Aceito em 27 de fevereiro de 2008 